\title{
Editorial
}

We have ten papers from various parts of the world and we wish to welcome especially a paper from Japan, p. 135, by Sister Hilary Ross who formerly did such good work at Carville, U.S.A.

We have been very fortunate in having the first annual report of the Lepra Control Project, Malawi, with the permission of Lepra and the Director of the Project, Dr. B. D. Molesworth, p. 200.

We draw attention to Dr. Meny Bergel's interesting discussion of Lysosomes on p. 189.

\section{Ninth International Leprosy Congress}

SEPTEMBER 16th-21st, 1968

Attention is drawn to the insert enclosed in this issue of Leprosy Review giving details of the arrangements for the Ninth International Leprosy Congress. 